\title{
Industrial Activity in a Rural Environment
}

\author{
Bernhard O. Zweifel
}

\begin{abstract}
UCB, a Belgian pharmaceutical/chemical company, founded an industrial site in 1996 in Bulle, Switzerland. Since the time of the creation of the enterprise, industrial activity has been expanded continuously and consists today of three production buildings with more than 70 employees in production and approx. 180 in total. In a preface to the description of the manufacturing activities some general remarks are made to highlight factors to be considered for a successful site selection. The conclusion is reached that the investment - as of today - has successfully met the expectations of the investor.
\end{abstract}

Keywords: Industrial site selection · Pharmaceutical active ingredients ·

Simulated bed multi-column chromatography

\section{Introduction to Site Selection Criteria}

UCB SA, a Belgian pharmaceutical/chemical group with its head offices in Brussels, founded a new industrial site near Bulle (FR) in Switzerland in 1995. The first production building was commissioned in 1996 and the activity has been expanding ever since. Today the production comprises three production buildings, two for the production of active pharmaceutical ingredients and one for the manufacture of film-coated tablets in bulk by direct compression.

The decision for a suitable location for a pharmaceutical factory has to be based on a series of quantitative but also qualitative elements. First it has to be taken into account that the manufacture of fine chemicals is in many aspects different from the production of mass products. Standard arguments, i.e. closeness to sources of raw materials and markets, cheap energy and labor, etc., have to be weighed differently if a site for the production of active pharmaceutical ingredients (API) has to be selected. Key success factors for the production of APIs of adequate quality with high reliability depends more on the level of education and the work ethics of the workforce, and the reliability of equipment and services. Furthermore a favorable economic environment with predictable approval processes for the necessary authorizations is a must. Manufacture of tablets that consistently meet the rigid quality standards of a heavily regulated industry is certainly different from producing commodities or consumer goods that are subject to constant change.

Some of the straightforward quantitative factors are certainly tax rate, stable exchange rate, labor costs and unemployment rate, energy costs, transportation costs etc. Weighing these factors in a decision analysis for selecting a production site depends on the type of production (Table). An industry with high capital cost will favor locations with low interest rates; manufac- ture which is labor intensive will look for countries with low labor rates. But things are more complicated: An industry that requires heavy investments should also look for locations where high productivity can be expected [1]. Under these circumstances a well-trained, motivated, and reliable workforce is needed which will allow the required quality to be reached consistently and guarantee adherence to safety standards.

The production of modern active pharmaceutical ingredients is based on complex organic chemistry processes. Organic chemistry is the key to economic processes for the production of fine chemicals [2]. In addition the complexity of the equipment needed for batch production in multi-purpose installations requires skilled professionals to install and maintain equipment that permit the achievement of the required high-quality standards. A plant meeting these requirements seems to be better located in a country like Switzerland than elsewhere. Here we find a long tradition of
${ }^{\star}$ Correspondence: Dr. B.O. Zweifel UCB Farchim SA

Z.I. de Planchy

P.O. Box 411

10, Chemin de Croix Blanche

$\mathrm{CH}-1630$ Bulle

Tel.: +41269190393

Fax: +41269190348

E-Mail: bernhard.zweifel@ucb-group.com

Table. Aspects of different types of production

Fine Chemicals

Labor cost

Capital cost

Fexibility in production

Energy consumption

Process risks

Potential impact on environment

Occupational hygiene
Bulk Tablets

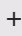

$++$

$+$

$+$

$++$

$++$

$++$

$++$

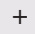

$+$

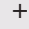

Packaging

$++$

$++$ 


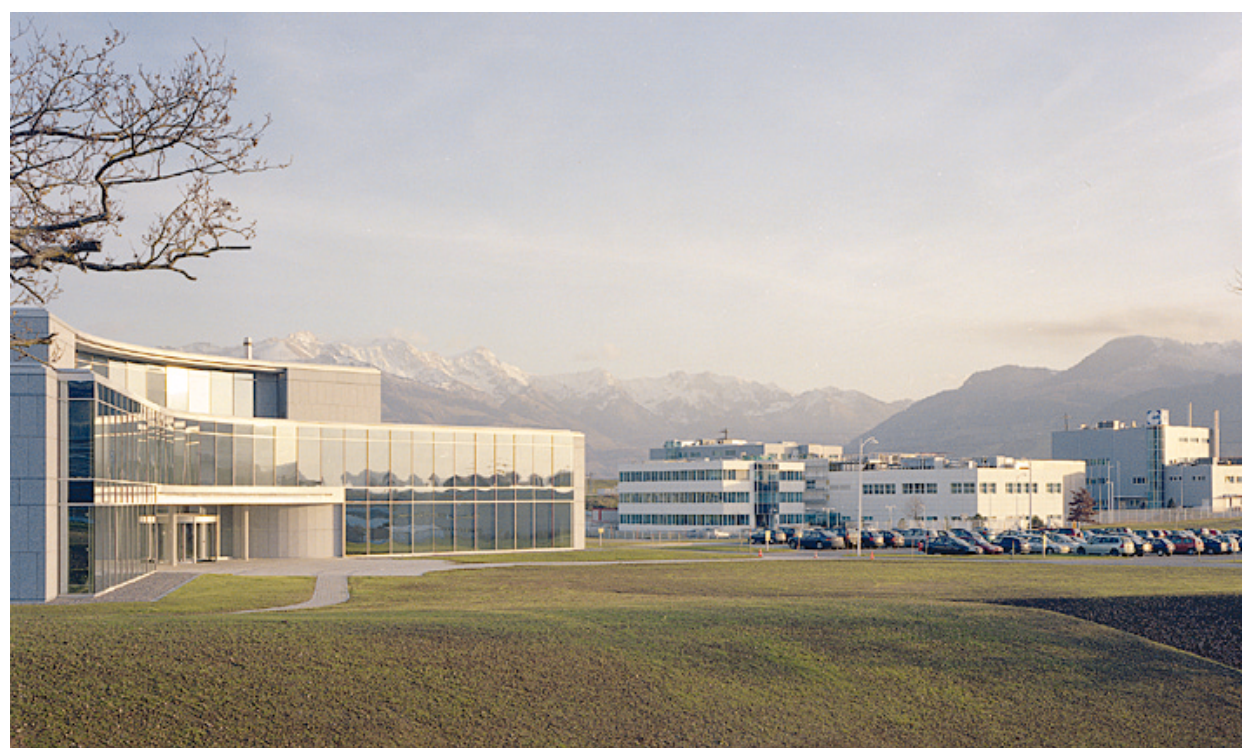

Fig. 1. Administration building and plant modern organic chemistry with all the support necessary for industrial scale production of modern APIs. Prerequisite for this is not only the availability of organic chemists with third level degree education but also the professional organizations that foster an innovative environment with platforms for the exchange of ideas. We also find a long tradition of excellent relations between industry and academia.

Selecting a site in Switzerland for pharmaceutical (galenic) production is less obvious. The influence of labor costs plays a more important role than for the chemical production of APIs. But among other aspects, productivity and flexibility of the workforce as well as the advantages of having formulation on the same site as chemical production can eventually tip the balance for such a decision.

\section{Description of Installations}

UCB Farchim SA is situated on a $65^{\prime} 000$ $\mathrm{m}^{2}$ area in the industrial zone of 'Planchy d'Avau' in Bulle. The immediate neighborhood consists of an agricultural and an industrial zone. Apart from two administrative buildings the site consists of three manufacturing buildings, a warehouse and a tank farm (Fig. 1).

The first building was built during 1995 and 1996 and is dedicated to pharmaceutical production and quality control laboratories. The area used for pharmaceutical production today will be converted into a facility for galenic development in the very near future. A new building for pharmaceutical production is under construction and year. It has a surface of $2300 \mathrm{~m}^{2}$ on three floors (two production floors and a basewill be commissioned by the end of the ment). The layout of the building has been designed to allow production of several different products simultaneously with no risk of cross-contamination and has been optimized for product flow. All major products formulated as tablets of the UCB group can be produced. The technology used for the production of film-coated tablets in bulk is dry granulation and direct compression. Sophisticated technologies are employed to produce bi-layered tablets; an achievement for which the company received a special prize at the 'Prix à l'Innovation du Canton de Fribourg' contest in 2003.

The warehouse with a surface area of $2100 \mathrm{~m}^{2}$ is located adjacent to the pharmaceutical production in order to facilitate the flow of materials. Storage capacity is more than 2000 pallets. A separate tank farm and a storage area for solvents in drums, liquids

The first building for chemical production was erected during 1996 and commissioned in 1997. Today it features three production lines, two for the chemical synthesis of APIs and their intermediates, one for the chromatographic separation of enantiomers. The technology employed for the separation of the isomers is 'simulated moving bed chromatography' (SMB) which allows the complete separation of the two enantiomers (Fig. 2). The equipment installed for the synthesis of the APIs and their intermediates is destined for conventional batch reactions. A building height of $17.2 \mathrm{~m}$ facilitates arrangement of the vessels in a way that allows the use of gravity for transfer operations. The two production lines are identically equipped with reactors, crystallizers, centrifuges and dryers; they share a decanter. Charging reactors with solids is done under laminar flow hoods. For the handling of the product clean rooms are provided to avoid contamination of the products. A high degree of automated batch control permits operation of the vessels during $24 \mathrm{~h}$ with just one shift. The building offers $2700 \mathrm{~m}^{2}$ of surface including room for future expansion. The energies supplied to production are steam, cold water, pressurized air, demineralized water, nitrogen; waste water is collected, decanted and adjusted for $\mathrm{pH}$ before it is sent to the communal waste water treatment plant.

A second building for chemical production with a total surface area of $4000 \mathrm{~m}^{2}$ was built between 2001 and 2003. A largescale SMB and its auxiliary equipment was and gases are located nearby.

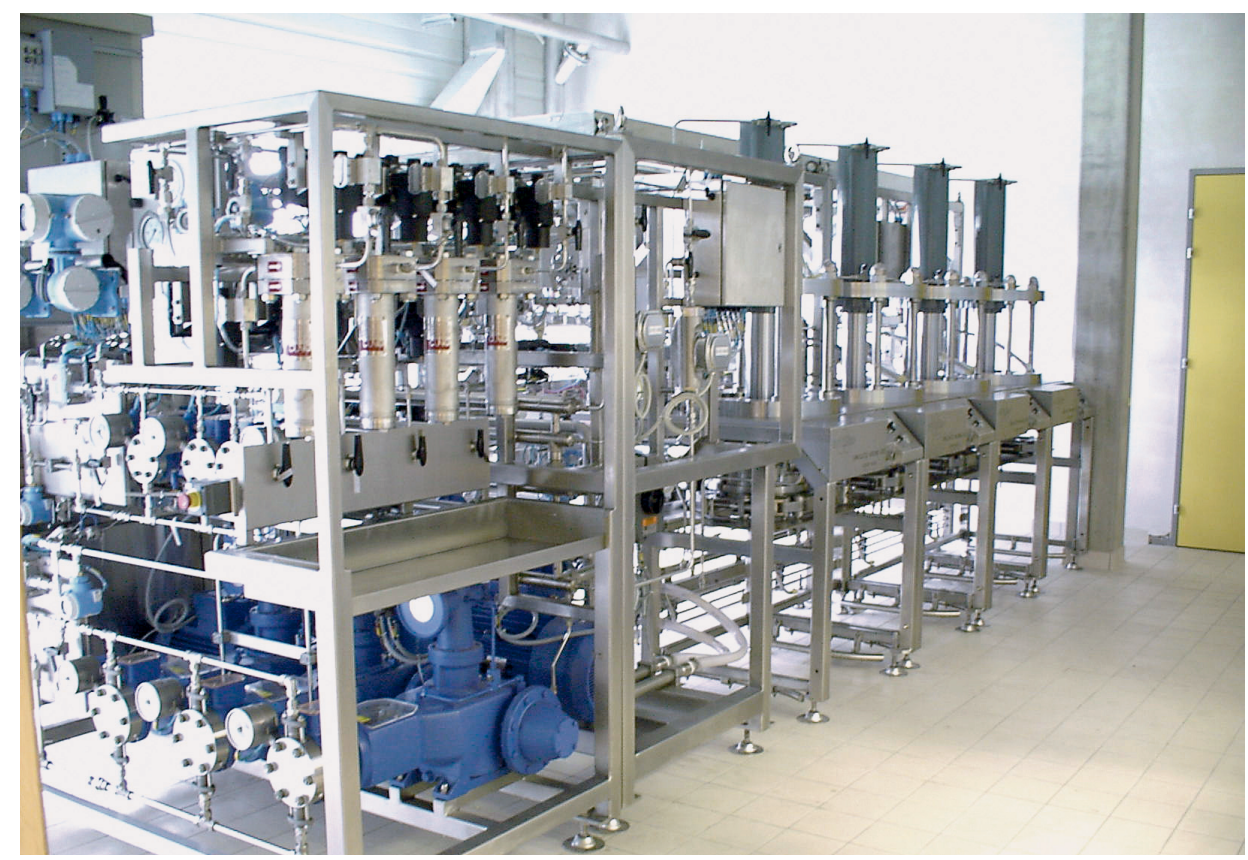

Fig. 2. Simulated moving bed chromatography (SMB) 
installed and commissioned in 2003. It will allow the separation of approx. $600 \mathrm{~kg}$ of enantiomeric mixture per day and will be operated in continuous mode. Currently a project is being realized to double the existing capacity and add a line for recrystallization of the desired crude enantiomer produced by the two SMBs.

Related services on site for support of production are quality control, quality assurance, engineering and maintenance, environmental protection, health and safety, purchasing and supply chain management. This brings the total of employees in technical operations to over 100 . It has to be admitted that at first it was not always easy to find qualified personnel. This is certainly due to the location with little related activity in the immediate neighborhood and to the fact that UCB was relatively unknown. Start-up would not have been possible without the support of experts from the UCB Group who have been transferred for temporary assignments to Bulle. With the growing reputation and the increased size of this industrial development it has become easier to recruit well-qualified employees.

The development of the site was facilitated by the excellent cooperation with the relevant authorities on all levels and good relations with the neighbors who looked favorably on the project of creating a pharmaceutical factory in a predominantly agricultural area. Instrumental to this was certainly UCB's commitment to employ state of the art technology respecting the environment. Proof of this attitude is the re-certification of UCB Farchim SA in 2004 according to ISO14000.

\section{Current Status}

In the seven years of the existence of UCB Farchim SA in Bulle the investment has met the expectations of the investor. The company has not only managed to meet highest quality standards according to the requirements of customers and authorities. The company was also re-certified according to ISO14000 in 2004. A favorable economic environment with support from the authorities has facilitated and accelerated the implantation of this pharmaceutical centre of excellence in the primarily agricultural region of La Gruyère. A highly motivated and dedicated workforce has achieved productivity levels that offset the higher labor cost in Switzerland. By now UCB Farchim SA is a magnet for wellqualified employees on all levels because of the attractive job opportunities it offers and the quality of life in a beautiful region idyllically situated between mountains and near Lake Geneva with the cultural and economic centers of Fribourg and Lausanne in close vicinity.

Received: November 2, 2004

[1] F. Martin, 'Comparative Analysis of Product Cost in Two Different Environments', Corporate MBA Thesis, University of Limerick, 1996.

[2] B.O. Zweifel, Chimia 2000, 54, 7. 